\title{
The relationship between management accounting systems and ERP systems in a medium-sized firm: a bidirectional perspective
}

\author{
Maria Serena Chiucchi ${ }^{*}$,Marco Gatti ${ }^{* *}$, Stefano Marasca ${ }^{* * *}$
}

Received: 19 January 2012

Accepted: 29 October 2012

\begin{abstract}
$^{1}$
The relationship between ERP systems and MAS is a relevant topic for accounting scholars. This relationship has often been studied by observing the influence of the implementation of ERP systems on MAS in terms of its impact on accounting tools, available information or the accountant's role. A limited number of studies have explored, instead, the inverse relationship, namely that one concerning the way MAS can influence the design, the implementation and the use of ERP systems. This paper aims to contribute to filling this gap. The bidirectional relationship between ERP systems and MAS is analysed through a case study, carried out in a medium-sized Italian firm. The findings show that the context, in this case a medium-sized firm, can play a relevant role in influencing the way the ERP system implementation affects the MAS, especially with regard to the controller's role and tasks. At the same time, they also shed light on how the existing MAS, as well as the one which is influenced by the implementation of the ERP system, can shape the customization and the use of the ERP system.
\end{abstract}

Keywords: management accounting system, ERP systems, small and medium sized enterprises, interpretive case study

* Department of Management, Polytechnic University of the Marche, e-mail: m.s.chiucchi@univpm.it.

** Department of Management, Polytechnic University of the Marche, e-mail: m.gatti@univpm.it.

**** Department of Management, Polytechnic University of the Marche, e-mail: s.marasca@univpm.it.

${ }^{1}$ The authors wish to thank the anonymous reviewers for their useful comments and the Editors for the helpful suggestions. Although this paper is the result of the joint work of the authors, the individual contributions are as follows: Maria Serena Chiucchi - parr. 4.1., 4.2. and 7; Marco Gatti - parr. 2, 3, 6.1 and 6.2; Stefano Marasca - parr. 1, 5 and the Appendix 1. The three authors jointly contributed to the "Discussion and Conclusions" paragraph. 


\section{Introduction}

The complex relationship between the Enterprise Resource Planning (ERP) systems and the Management Accounting Systems (MASs) has been the object of many studies in recent years. A large part of the research has investigated this relationship considering the ERP system as the independent variable and the MAS as the dependent one (Grandlund and Malmi, 2002; Grandlund and Mouritsen, 2003; Scapens and Jazayeri, 2003). From this perspective, studies have been carried out with the aim of investigating how the implementation of an ERP system can affect different aspects of a MAS like, for instance, the number and the nature of techniques, the perception of the MAS as well as the controller's tasks and competences (Caglio, 2003; Lodh and Gaffikin, 2003; Grabski et al., 2009). A good number of these studies were carried out in large companies where ERP systems are more widespread. In fact, costs and time needed to implement ERP systems can be more easily coped with in these particular contexts than in small and medium-sized enterprises (SMEs).

In recent times, studies have brought to light the need to increase the knowledge on this topic. In particular, authors have stressed the idea that the relationship between ERP systems and MAS cannot be explored only in terms of the influence that the former can have on the latter. Rather, by observing that this relationship is bidirectional (Luft and Shields, 2003; Rom and Rohde, 2007; Wagner et al., 2011), they have argued that new research should be done in order to explore how the MAS is able to affect the design, implementation and use of an ERP system. At the same time, research has also underlined the need to study this relationship in different contexts, i.e. small and medium-sized firms (Hyvönen, 2003). This can be useful in order to understand how these relationships manifest themselves and develop in a context in which the MAS, as well as the ERP system, can be perceived differently than they are in large companies.

The paper is aimed at answering these calls by exploring the implementation of an ERP system within an Italian medium-sized firm. More specifically, the research is conducted through a case study, referred to SAP implementation. The whole implementation process and the period that followed it, referred to its use, are analyzed in order to explore, on the one hand, how the MAS and the accountant's role were shaped by the SAP implementation and, on the other hand, how the MAS affected the design and the use of the ERP system.

This paper is organized as follows. Section two and three provide a brief literature review of previous studies on the relationship between ERP systems and MAS and on the features of SMEs which can influence it. Section 
four illustrates the research method and section five introduces the company, its MAS before the SAP implementation and the reasons why SAP was chosen. Section six analyzes the impact that SAP had on the existing MAS as well as on the controller's competences and tasks. Section seven explores the way the company MAS influenced the ERP system and some findings that were peculiar to the case study are discussed. Finally, concluding remarks are provided in the last section.

\section{The bidirectional relationship between ERP systems and MAS}

In recent years, the academic debate on ERP systems has flourished. The relevance that ERP systems have gained in modern organizations has led scholars to study their implementation process as well as the consequences that arise from their adoption. In particular, they have focused attention on factors that can influence the effective implementation of ERP systems and on the financial and organizational impact of their introduction (Gupta, 2000; O’Leary, 2000; Poston and Grabski, 2001; Hunton et al., 2003; Umble et al., 2003; Nicolau, 2004, Matolcsy et al., 2005, Ifinedo, 2008; Kamhawi and Gunasekaran, 2009). More recently, a growing number of studies have paid attention to the role that ERP systems play with regard to MASs (Hyvönen et al., 2008; Grabski et al., 2009; Schlichter and Kraemmergaard, 2010). The interest in this topic is linked to the fact that ERP systems, or in general, information technology, and MASs can be considered substantially co-dependent (Dechow et al., 2006). To date, a large body of studies has explored this relationship focusing on one direction, namely how the implementation of an ERP system is able to affect a company MAS, triggering a process of change (Grandlund and Malmi, 2002; Scapens and Jazayeri, 2003, Hyvönen, 2010).

In keeping with this "unidirectional" perspective, studies have investigated how a MAS changes when a new ERP system is implemented, shedding light on the impact of the implementation of an ERP system on MAS techniques, on its usage and on the accountant's role within the organization. Empirical studies have demonstrated that ERP systems have a limited impact on the adoption of new techniques. In fact, the number and the nature of management accounting techniques remain almost unaltered after the implementation of an ERP system (Grandlund and Malmi, 2002; Scapens and Jazayeri, 2003; Jack and Kholeif, 2008). According to Grandlund and Malmi (2002), this limited impact can be due to the fact that the implementation of an ERP system is a time-consuming activity and it takes time to observe its effects. They also state that the complexity of an ERP 
system can limit the adoption of other accounting innovations and that, in some cases, ERP systems can also reinforce the existing routines rather than lead to the implementation of new ones.

Many studies have also explored how the role of the management accountant changes when an ERP system is implemented (Jack and Kholeif, 2008; Hyvönen et al., 2009; Sangster et al., 2009). They have pointed out that the implementation of an ERP system generally leads to the standardization and the elimination of some of the routine activities carried out by management accountants and, as a consequence, it frees up a lot of time in the Accounting Department (Caglio, 2003). This is also demonstrated by studies that show how a reduction of personnel in the accounting department normally follows the implementation of an ERP system (Poston and Grabski, 2001; Umble et al., 2003). At the same time, a large number of studies highlight the radical change in the management accountant's role within the organization as being one of the most relevant consequences of an ERP system implementation; in particular, they underline that the accountant moves out of the role of "beancounter", or bookkeeper, into that of business analyst (Quattrone and Hopper, 2001; Caglio, 2003; Lodh and Gaffikin, 2003; Scapens and Jazayeri, 2003). In this view, the controller acquires a relevant role in supporting top management and its decisionmaking processes through the use of the large quantity of information that an ERP system is able to provide. Caglio links this phenomenon to what she calls the "hybridization" of the controller. In fact, in her article, based on a case study research, she observes that, after the implementation of the ERP system, the management accountant acquired new competences normally pertaining to the financial accountant and to the IT professionals.

Studies have also showed that, after the ERP system implementation, accountants often need to deepen their knowledge, with regard to IT, and to develop new skills in order to be able to manage such a complex system (Caglio, 2003; Lodh and Gaffikin, 2003). Among these skills, the ability to select the most relevant information and to adequately present it in the reports prepared for top management seems to be particularly important (Dechow et al., 2006).

Recently, research has begun to explore the relationship between ERP systems and MASs also considering the "other direction" which, up to now, has been somewhat neglected. Therefore, attention has been turned on how the MAS could be able to affect the ERP system (Luft and Shields, 2003; Rom and Rohde, 2007; Wagner et al., 2011). In this view, the MAS and the way it is used, as well as the actual accountant's role within the organization, are investigated as factors able to influence the design, the implementation and the use of an ERP system. Research is still in an embryonic stage 
and, therefore, the way this relationship develops has not been clearly identified and the number of empirical studies is still limited. Rom and Rohde (2007), in particular, highlight the fact that the MAS can affect the ERP system before and after the implementation phase. In fact, before the ERP system is implemented, the company chooses among different options and of these, it can also choose those which permit keeping the status quo and which allow it to forge the system according to the previous MAS. On the contrary, if the company takes advantage of the ERP implementation to change the MAS, once the employees become accustomed to it, it is likely that they will try to change it by way of small improvements. Adding to this, Wagner et al. (2011) show that the ERP system can also be heavily customized if users feel dissatisfaction with the "new" MAS, namely that one which is affected by the ERP system implementation.

\section{SME's features and their impact on the MAS}

Recently, it has been underlined the need to explore the bidirectional relationship between ERP systems and MAS paying attention to a specific aspect which deserves further investigation: the context in which ERP systems are implemented (Hyvönen, 2003). The majority of studies, in fact, concerns the implementation of ERP systems in large organizations since the adoption of these complex information systems can be difficult and therefore rare in SMEs for many reasons, such as lack of financial resources, inadequate IT training, etc. (Hill, 1997; Ferman, 1999; Muscatello et al., 2003) ${ }^{2}$. There is a need to enlarge the nature of the contexts in which the relationship between ERP systems and MASs is explored, especially with regard to SMEs where MASs can be substantially different from large firms, in terms of techniques, usage of information and accountants' role. Existing studies have already explored the design and the implementation of MAS and management control systems in SMEs. By adopting a contingency perspective, they have underlined that the size can heavily influence the form of control used. In particular, SMEs seem to be more used to adopting personal control and, broadly speaking, simple and unsophisticated information systems (Bruns and Whaterhouse, 1975; Merchant, 1981; Libby and Waterhouse, 1996; Guilding, 1999)

2 According to the taxonomy proposed by the European Union recommendation 2003/361, in this paper medium-sized firms are understood as those which employ fewer than 250 people and which have an annual turnover not exceeding 50 million Euros and/or an annual balance sheet total not exceeding 43 million Euros. 
Studies which have adopted a contingent approach to demonstrate that company size can influence some features of the MAS have substantially failed to explain the reasons why this happens. In order to provide a full explanation of these reasons, several qualitative research studies have been carried out. Barretta (1999), for instance, showed that the adoption of a simple and informal MAS in SMEs can be largely attributed to three main factors:

- the presence of a governance system in which the owner is fundamental as he tends to centralize the power and, as a consequence, to use the MAS to support his decision-making process rather than to orient people's behavior;

- the lack of a clear definition of tasks and responsibilities among people which makes it difficult to control people's results by using formal tools;

- the high degree of informality which characterizes these contexts and which also influences the shift towards the use of informal control systems, like the clan control, rather than the formal ones.

It has also been underlined that SMEs often lack an organizational culture oriented towards control (Riccaboni, 2004). For instance, there is no perceived need to adopt a sophisticated MAS because the owner is deeply involved in several activities and, in some cases, he has no time or he is not interested in paying attention to questions concerning the implementation of a management control system (Barretta, 1999). Finally, the lack of financial resources can reinforce the limited use of MASs and the adoption of useful information systems.

In summary, qualitative and quantitative research has shed light on how the distinctive features of small and medium-sized firms can affect the implementation and the use of MASs and of advanced MAS. As a consequence, in the next sections they will be taken into consideration in order to understand if and how they affected the bidirectional relationship between ERP systems and MAS.

\section{Research method}

\subsection{The interpretive approach}

This paper aims to contribute to the research on the bidirectional relationship between ERP systems and MASs especially focusing attention on the "direction" which has received less attention so far, namely the influence that the MAS can have on the ERP system. To conduct this investiga- 
tion an exploratory case study, referred to the design, implementation and use of SAP in a medium-sized Italian company, will be presented.

Consistently with a part of the literature, the introduction and the use of an ERP system is understood as a complex phenomenon in which human and non-human actors interact and construct the reality they live in (Grandlund and Malmi, 2002; Caglio, 2003; Grandlund and Mouritsen, 2003; Lodh and Graffikin, 2003; Scapens and Jazayeri, 2003; Dechow and Mouritsen, 2005; Wagner et al., 2011). Implementing an ERP system in an organization which was accustomed to using a legacy IT system means introducing a tool which presents characteristics and an underlying logic that are "new" for the people who use it. Therefore, when an ERP is introduced within a company, it influences the way people do their job, their everyday actions, the way they perceive their activities, the reality that surrounds them and their role in it; in other words, it affects their behavior and perceptions (Alcouffe et al., 2008). In turn, people's behavior, perceptions and use of the ERP system influence the ERP system, as well.

Following these assumptions, the case analysis will be conducted using the interpretive approach which has been widely applied in social sciences (Scapens, 1990; Ahrens and Dent, 1998; Denzin and Lincoln, 1998; Guba and Lincoln, 1998; Corbetta, 2003; Fattore, 2005). The adoption of this approach is useful for the aims of this paper because it suggests studying management accounting within the social, historical, economical and organizational system in which it develops, which it influences and is, in turn, influenced by (Burchell et al., 1985; Ryan et al., 2002; Ahrens and Chapman, 2007).

In short, the interpretive approach considers that there is not an objective world that exists independently from human beings: reality is socially constructed and, therefore, each person perceives and interprets reality his own way and gives his own meaning to social phenomena. This implies that there are multiple realities: the same phenomenon, in fact, can have different meanings for different people. According to the interpretive paradigm, observations are dependent on the person who makes them and the aim of inquiry is to understand, interpret, explain and clarify the meaning embodied in the language and actions of individuals, making sense of human actions and of the meanings attributed to them and to social phenomena. Therefore, it is impossible to find general laws: all the aspects that characterize a phenomenon interact simultaneously and are contextualized in time and space. As a consequence, social phenomena can be explained only in terms of what they mean to people who are responsible for them.

Considering all the above, a coherent story built upon the case material will be presented. Verbatim quotes from conversations or interviews with 
the social actors will be used to allow the reader to gain insight on the passage from the words heard to the theoretical interpretation.

\subsection{Data collection and analysis}

As far as the case study process is concerned, for a question of length, only some of the critical issues faced in accomplishing the fundamental steps which make up this kind of research will be commented here ${ }^{3}$. The case company was selected purposefully (Patton 1990) and the reasons why it was chosen are several. In particular, it is worth highlighting that the authors had been conducting research in this company for several years before this study was begun and, during that time period, issues regarding the ERP system, its use and its relationship with the company MAS had repeatedly and spontaneously emerged either in formal interviews or in informal chats and observations. Therefore, the company seemed to be a fruitful field in which to investigate the issue at hand. Moreover, the fact that the company was medium-sized, that it had implemented an ERP system and that three years had passed since the system had gone live, thus permitting observation of its effects, appeared to provide a good opportunity to contribute to filling the theoretical gaps mentioned in paragraphs two and three.

The empirical data were collected primarily through semi-structured interviews and analysis of company documents such as organizational charts, job descriptions, SAP blueprints and internal documents. In total, 47 documents were analyzed. Interviews, instead, were carried out in 2011 when the ERP system was fully implemented and was widely used by people within the organization. In total, 7 company key persons were interviewed, among them, the General Manager (GM) who was also the head of the Sales Department, the Head of the IT Department and the owner. The Controlling Consultant was also interviewed since he had an active role in designing and improving the MAS. The interviews were aimed at understanding what people thought of the ERP system, its usefulness, its impact on their tasks, on the MAS and vice versa. These interviews were fundamental since they allowed the researchers to look at the bidirectional relationship

${ }^{3}$ Several authors have proposed and analyzed the steps which make up the process of developing a case study research. A 'typical' sequence which takes into account the proposals put forth by authoritative scholars (Eisenhardt, 1989; Scapens 1990 and 2004; Yin, 2003) is the following (Chiucchi, 2009, pp. 23-25): establishing the research questions, selecting the cases, preparing to collect data, collecting data in the field, analyzing the data and reporting the findings. 
between the ERP system and the MAS from different perspectives, namely that of the people who use the MAS and of those who manage it, like the controller. Sixteen taped interviews were conducted, with an overall length of 39 hours. A large number of them were transcribed into written form to facilitate their analysis. The number of questions in each interview varied but they all revolved around the impact of the ERP on the interviewees' activities, on their tasks and competencies as well as on those of other people who worked in their unit and reported to them. At least two researchers usually took part in the interviews. Once they were transcribed, each of the researchers analyzed the interviews, took notes and drafted a categorization of the information gathered. Then, the researchers discussed and compared their respective notes (and this allowed new categories to arise) to discern possible patterns and connections from the evidence collected.

Moreover, other sources of information were used in order to provide a full interpretation of what resulted from the abovementioned interviews and to triangulate, when possible, the data collected. The adoption of an interpretive approach, in fact, implies the analysis of the context in which accounting works. In light of this, the analysis benefited also from the information collected by a $\mathrm{PhD}$ student, who followed the whole ERP system design and implementation, through semi structured interviews and a questionnaire aimed at investigating the impact of the ERP system on company employees' tasks and relationships. This information was used in order to make sense of what happened and to shed light on the specific context which can have influenced the relationship between ERP system and the MAS. Moreover, it has to be highlighted that the authors had been doing research in this company, during the previous years, for different aims compared to those this paper refers to. Therefore, empirical data collected in that occasion were reviewed to search for information that could be useful to integrate or to triangulate the empirical data drawn from the interviews or from the document analysis.

\section{The case background}

Tulip S.p.A. is a medium-sized Italian manufacturing company operating worldwide and whose production system is based on job orders.

The company MAS, before the SAP implementation, was very simple and predominantly focused on financial information. It was substantially based on three main tools: a budget, a cost accounting system and a managerial reporting system. The management accountant was the person who managed these tools but his role was primarily that of an information provider. 
SAP was implemented in 2005, after a software selection which took place from January 2004. The decision to adopt this ERP system was linked to technical aspects since SAP was the only system which allowed Tulip to incorporate in the new ERP system the so called "product configurator", which was the heart of the company information system. At the same time, the decision was also due to the belief of the company owner that SAP was the best in class. This strong sponsorship contributed to reinforce the perception among people that it would have been able to fulfill the company needs and to improve the company MAS as well as the quality of the information that it provided ${ }^{4}$.

\title{
6. The influence of SAP on the company MAS
}

\subsection{The influence of SAP on the management accounting tools}

Broadly speaking, the SAP implementation made managerial control and administrative tasks easier in Tulip. After the implementation of the new ERP system, in fact, the number of administrative employees decreased by about a quarter.

From a technical point of view, the main tools remained substantially the same: the budget, the cost accounting system and the reporting system. However, some of their features changed. With regard to the budget, which had been used within the company since the late Nineties, the most relevant change concerned the introduction of standards. Before the SAP implementation, budget costs were estimated considering historical costs as a point of reference. When SAP was introduced, the company decided to implement production standards: standard times and rates referred to set up and to the manufacturing process. They were used not only within the budget but also to carry out an ex ante job order profitability analysis.

\begin{abstract}
"When we decided to implement SAP, we also reflected on another relevant aspect, namely the opportunity to adopt standard costs or continuing to use historical costs. The need to know the margin of every job order acquired led us to adopt standard costs. But, using standard costs means putting new standard parameters into the product configurator. This was a completely new scenario for us because the previous product configurator didn't allow for the possibility of using standard costs."
\end{abstract}

[Company Controller]

${ }^{4}$ Further information about the company profile, the existing MAS and the factors which drove the decision to implement SAP is provided in the appendix 1 section. 
It is important to underline that the shift toward the use of standard costs rather than historical costs did not represent only a MAS improvement from a technical point of view, but it also changed the way budget information was perceived by people and by the controller within the organization. The latter, in particular, considered it to be a "revolution" for the company MAS and he stressed the importance of the higher reliability of the data used which were potentially able to provide a more reliable budget.

The other tool which was part of the MAS was the cost accounting system. Before the SAP implementation, it was aimed at calculating the marginal cost of job orders. The SAP implementation, instead, favored the calculation of a "new" product cost concept: the full production cost. The GM, in fact, was not comfortable with the contribution margin which could be calculated by the previous MAS. He believed full production cost to be the right information to be used in order to analyze product profitability. The abovementioned shift from the marginal cost to the full production cost was possible because SAP provided the opportunity to enlarge the functionalbased accounting system, adding some service cost centers to the existing production cost centers.

The last relevant tool that was part of the MAS was the reporting system. By using SAP, the controller was able to provide more information and, as a consequence, he decided to enrich the existing reports, namely the institutional and the production report. At the same time, new specific ones were prepared with the aim of focusing attention on some of the most relevant raw materials costs. Therefore, the quantity of information provided as well as the degree of detail grew rapidly. This increase was so relevant that gradually, after the SAP implementation, the need to select data became a critical issue among top management.

\footnotetext{
"Today the paradox is that we have too much information. Now the problem is to make a synthesis, an effective synthesis. With ERP systems the problem is this: you have a huge quantity of data, so you have thick reports that are overwhelming. The most difficult thing is to understand what the key indicators are and to focus attention on them."
}

[Company CFO]

In addition to the criticism for the overwhelming quantity of data, the report format was also criticized since it made the reports difficult to read and focusing attention on the relevant data was not simple. In fact, information was presented as it was provided by SAP without making any changes: reports were full of tables containing long lists of numbers. 


\title{
6.2. The influence of SAP on the controller's role
}

Turning the attention toward the impact of SAP implementation on the controller, it is possible to make a distinction between his tasks and competences with the latter showing limited improvement, as the company controller stated:

\begin{abstract}
"My competences have not increased. From an IT standpoint I had already acquired a high level of skills in using the previous software and now I've improved them a bit, thanks to SAP. I must also say that many IT issues that I had to manage when we used the ACG of IBM, now are automatically managed by SAP. I can say that there has been an improvement in my IT skills but it was not significant because I already had good competences. Nothing has changed with regard to my specific competences, as a controller I mean. What has changed is the codification of my job. SAP asks you to codify everything you do in your job: all the steps needed to perform a certain activity are codified and, if you don't do something, SAP is not able to provide the requested information. So, there was a codification of my job, but this has nothing to do with my competences.”
\end{abstract}

[Company controller]

From the last verbatim quote, it emerges that the controller thought he did not experience any improvement in his accounting competences and only a limited improvement in his IT ones.

Nonetheless, at least for his IT skills, other employees' perception was completely different. He had been so deeply involved in SAP implementation that he started to be considered the "SAP expert" by his colleagues.

\footnotetext{
"At the beginning everybody bothered me. There was a period of 3 or 4 months during which people asked for my help, although everything regarding SAP was codified in the manuals [...] Still there are some requests for help, even if, of course, they have decreased a lot. I am a sort of SAP key user. I am considered a SAP internal consultant.”
}

[Company controller]

From this perspective, despite what the controller thought about his competences, after the SAP implementation people began to refer to him not only for his role as a controller but also as the person who was supposed to solve problems related to SAP. Therefore his reputation increased although it concerned the SAP technical functioning rather than his role as a controller within the organization. 
With regard to his tasks, the controller underlined the fact that the activities he carried out after the SAP implementation had changed significantly. The "change" was substantially associated to the fact that the controller did not have to verify the data provided by the new ERP system: they were "correct" and "certified" as it was frequently said by interviewees.

Furthermore, the controller perceived his tasks to be easier than before:

\footnotetext{
“My activity is easier now. I don’t need to spend my time controlling data, verifying their reliability. I don't carry out these activities any more. [...] The controller's tasks has been made easier by SAP."
}

[Company controller]

Although SAP allowed the controller to have more time to dedicate to other activities, in Tulip this was seen as an opportunity to increase his involvement in routine administrative tasks such as book entries or invoice control, in particular. This seems to be due to the fact that, two years after the SAP implementation, the organization chart changed and he became part of the Administrative and Finance Department, so his new Department Head was the CFO, rather than the GM who had been up to that moment. As a matter of fact, this change had a considerable impact on the nature of the activities carried out by the accountant. As stated by the CFO:

"In our company, the controller is an employee of the administration office who is called upon to carry out control activities too. Fundamentally he's a controller, but he must also carry out administrative activities, if necessary.”

\section{[Company CFO]}

In this case, the controller was seen as a multitasking person, able to carry out different administrative activities and not only the controlling ones. The fact that he was called to carry out tasks pertaining to different roles is consistent with a particular feature that Tulip shares with many other medium-sized firms: usually, in fact, in these companies employees' roles are not clear-cut and are also defined according to people's competences (Marchini, 1995; Franco and Bourne, 2003; Marchi, 2009).

On the contrary, the fact that he has been asked to carry out routine administrative tasks is strictly related to the specific company. Literature has shown that cultural factors, linked to the way managerial control is perceived within the organization, can influence the adoption and the use of a MAS in a small and medium-sized firm (Riccaboni, 2004). In Tulip, the control culture has always been focused on financial data as the primary 
source of information through which results can be analyzed and the company activity managed. In this perspective, the importance given to financial data can have played an important role with regard to the controller's tasks after the SAP implementation by re-directing his time towards those activities which were necessary in order to provide the abovementioned data, namely administrative rather than control activities.

\section{The influence of the company MAS on SAP}

In order to explore the influence of the company MAS on SAP it is useful to adopt two different perspectives. The former concerns the role that the existing MAS plays in shaping the design, the implementation and the use of a new ERP system. The latter, instead, focuses on the analysis of the impact that the "new" MAS, that is to say the one which emerges after the ERP system implementation and which is influenced by the choices made, has on the re-design as well as the use of SAP.

In Tulip, the existing MAS had a strong influence on the ERP system through the implementation of the "product configurator". As observed above, it was the heart of the whole information system and of the MAS as well and, for this reason, the company wanted to replicate it in the new ERP system. From this perspective, the existing MAS played a fundamental role in shaping the new ERP system because the configuration options were selected in order to be consistent with the "old" MAS logics. This ensured a continuity with the existing MAS on the one hand and, on the other hand, instead, it limited the full exploitation of the advantages that SAP would have been able to provide with regard to the company MAS. In essence, the fact that the old MAS logics were replicated within the new ERP system led to an original strong SAP customization but also to have a "new" MAS which was not substantially different from the existing one. The "new" MAS was perceived as a system able to provide more reliable information than the previous one. This was linked to the fact that information would be produced by the new ERP system rather than through Excel spreadsheets and this should have limited the risk of making mistakes.

In light of the abovementioned expected reliability of the "new" MAS, after SAP's "go live" period, the GM decided to evaluate the possibility of managing the sales quotation system through the new ERP system, thus using the data processed by the "new" MAS. He thought of this SAP customization as "the last piece of the puzzle" that would be put into place. Notwithstanding these intentions, nothing happened for more than three years. 
Up to 2011, in fact, the sales quotation system continued to be managed through a legacy system rather than by SAP. The full production cost which it produced was different (higher) than the one considered "fair" by the GM and calculated using the sales quotation legacy software. For this reason, the GM did not use the full production cost to quote sales but, despite this, the validity of this information was not immediately questioned.

The main explanation for this situation is that the GM considered it to be a problem related to the way data were shown rather than to their reliability and this perception was reinforced by the problems the company was experiencing with the income statement. Every month, in fact, the controller and the CFO were expected to produce two income statements, referred to the previous month, addressed to the GM and to the owner. The controller's monthly income statement had to be delivered to the GM no later than one week after the end of the analyzed month, therefore, in this statement, full production costs were calculated using standard costs. The CFO's income statements, instead, could be delivered ten days later and, since actual costs referred to the analyzed month were usually already available, they were included in this statement. It systematically happened that the bottom line of the controller's monthly income statement was higher than the other one and this difference kept increasing over the two years. This situation was the main cause of the deep dissatisfaction of both the GM and the owner, in particular. Nevertheless, the increase in the difference was not seriously questioned, at least not initially.

The company controller was conscious that the discrepancy was due to the use of standards costs which were not updated and this led to an underestimation of the full production cost. As a consequence, he simply highlighted the amount of the variances at the bottom of his income statement. The technical explanation given to the GM and to the owner was that, at the end of the year, profit (or loss) in the two income statements would be the same amount since the variances would have been assigned to products; this was equivalent to pouring oil on troubled waters, at least at the beginning. The GM and the owner as well understood the misalignment as a problem due to different ways of communicating the same data therefore it was not considered a high priority problem. Since the GM did not appreciate that kind of representation, the integration of the sales quotation system was postponed.

"I didn't do anything to sort it out because the controller and I never went through the data in depth. Actually he presented them through very long tables [...]. When I saw the variances I didn't attribute to them the importance 
they deserved because the controller told me that at the end, they will be allocated to the products. Of course, I didn't give them the right importance also because my competences on these specific aspects don't allow me to understand their true meaning. But he knew what was happening and the reasons why we had those variances, so he had to inform me about it. When I understood the situation, I told him: “Are you joking? Do we have this amount of variances?”. I mean, the need to avoid this kind of problems was one of the main reasons for which we decided to implement SAP!

[Company GM]

As the GM states, probably the fact that he did not understand the accounting vocabulary used by the controller did not allow him to thoroughly grasp the "accounting meaning" of the words used and this favored the misconception of the problem as linked to the way the data were represented. Actually the management accountant and the managers gave different meanings and importance to the same words and concepts.

In addition, another determinant reason for postponing SAP customization seems to emerge from looking at the interviews. As stated above, in fact, managers expected the "new" MAS to be more reliable than the existing one and this was due to several aspects. One of the main reasons which drove the decision to implement SAP was that the latter was seen as a chance to improve the existing MAS. At the same time, the information provided through SAP was perceived as timely, precise, unique since it was obtained through a common source, easier to be found and more objective, because the production process, once defined, was definitely set and everybody had to follow it. Information was considered accurate and reliable especially because there was no possibility of manipulating it. The fact that it fostered interactions and data discussions among people was another advantage of the system that was also stressed.

\footnotetext{
"The system provides information about the relevant variances and I can see them as well as those who are responsible for them. Then, you can ask them why this has happened. The information provided by SAP is reliable. From this standpoint SAP can have influenced the way people discuss results, because SAP is a system that forces people to compare information with other people."
}

[Company CFO]

Managers thought that one of SAP's most important pros was that the information production process was, quoting their words, "ironclad", "certified”, and they really appreciated this. 
Nonetheless, in the perception of individuals, it seems that a sort of osmosis occurred between the process and the information (its output). In fact adjectives such as "certified", "reliable" and so on, were also applied to the information produced by SAP.

In short, for all the people involved the idea that data were "certified" by SAP acted as a sort of panacea. Since "SAP does not make mistakes" the validity of the information was not questioned at least in the early time period and the problems were attributed to different ways of representing data.

\begin{abstract}
"Today we have a reliable database because now we get all the information we need from SAP and, for this reason, the information is definitive and certified by the controller on the basis of clear criteria [...]. Everybody knows that the information provided by the system is $100 \%$ reliable. Moreover, people now have information that is much more timely and updated than in the past and this happens with regard to all the information provided to every different hierarchical levels within the organization [...]. Information is even more complete than in the past. A few years ago we needed to obtain data manually [...]. There is also another thing that I can personally confirm. Today, we don't have to check the data's reliability, of course I'm talking as the Head of the IT Department. Before the SAP implementation we needed to check and to verify the mistakes and to sort them out. This doesn't happen now. In SAP, when you have certified a process you can't change it: you must do it that way or you don't do it. When you have defined the procedures there's no way to make mistakes. Our activity now is not to check data but to provide new things, new applications and new tools."
\end{abstract}

[Head of IT Department]

Finally, this kind of perception was linked either to the strong image that SAP had on the market in that period and to the sponsorship that it was given from the owner. In Tulip the role of the owner proved to be fundamental, as in many small and medium-sized firms, as far as the company management and the decision-making processes are concerned. Sponsorship is one of the most relevant critical success factors for the implementation of an ERP system. Nevertheless, in this case, the presence of the very strong figure of the owner, the fact that he made the decision to adopt SAP and that he strongly believed in its pros appear to have influenced the system's reputation among users, their coming on board as well as their tendency to avoid questioning the data's reliability.

Taken together, the poor control culture and the strong reputation that SAP had within the organization could have acted as a "screen" behind which the real problems had been hidden. In this view, people's perceptions and expectations about the "new" MAS, substantially linked to the idea that they had about SAP, hindered the customization of the ERP system. 


\section{Discussion and conclusions}

The case analysis conducted throughout the paper contributes, on the one hand, to the understanding of the bidirectional relationship between ERP systems and MASs and, on the other hand, to increasing knowledge on how a specific context, that of SMEs, can influence the way the abovementioned relationship can develop.

Looking at the relationship between ERP systems and MAS from the "traditional" unidirectional perspective, the study shows that, in Tulip, the implementation of a new ERP system did not bring about radical changes in the management accounting techniques used and it also made the whole system easier to manage. This finding is consistent with previous literature on this topic (Poston and Grabski, 2001; Grandlund and Malmi, 2002; Scapens and Jazayeri, 2003; Jack and Kholeif, 2008). Nevertheless, it should be underlined that the ERP presented the opportunity to improve the company MAS by introducing standard costs and allowing it to provide a new relevant information for decision-making processes: the full production cost. Even if these can be considered "incremental" changes of the existing tools, they were perceived as very relevant by the company management (quoting the controller's words "epochal"). This can be largely due to several factors which Tulip shares with other SMEs like, for instance, the limited people's attitude towards control, the orientation towards financial data and the tendency to adopt simple and unsophisticated systems. Therefore, even if the ERP adoption could favor the introduction of advanced controlling practices, it is unlikely that it can drive changes that are not perceived as important by the users and it is also likely that "incremental" changes within existing practices are perceived as very relevant.

As far as the impact of the ERP system on the controller's role is concerned this paper shows that he widened the range of his IT competences but his specific competences as controller remained substantially unaltered. Therefore, contrary to what has been observed by the majority of the studies conducted so far (Quattrone and Hopper, 2001; Caglio, 2003; Scapens and Jazayeri, 2003), the controller did not experience any shift from the role of information provider to that of business analyst.

Therefore, this paper contributes to extant literature by showing that the ERP introduction does not necessarily lead to an evolution of the controller's role. Reasons for this can be largely traced back to the specific context, that of a medium-sized firm. In this case, in fact, while the absence of clear-cut roles may have emphasized the opportunities for competence enlargement, the control culture, "limited" and predominantly focused on 
financial data, may have favored the take up of routine administrative tasks rather than strategic ones. It is also necessary to underline that a contextspecific event, such as a re-organization of the Administrative and Finance Department (which brought the hierarchical subordination of the controller function to the CFO), strengthened the development trajectory of the controller's role towards the described direction.

This paper has also investigated the inverse relationship between ERP systems and MAS, namely that one which looks at the impact of the latter on the former by proposing to focus attention on two facets of this relationship: how the existing MAS can influence the ERP system before its implementation and on how the "new" MAS can affect the ERP system after its implementation. From the first perspective, the paper confirms that the existing MAS can play a pivotal role in shaping the design of an ERP system, thus limiting the MAS evolution itself which could potentially be brought about by the introduction of an ERP system.

From the second perspective, so far research has shown how the "new" MAS can influence the ERP system by promoting its customization (Wagner et al., 2011). This paper contributes to this literature by showing another way in which this relationship can develop: the "new" MAS, in fact, can also hinder the ERP system changes. In the case under analysis, the dissatisfaction with the new product cost information (full production cost) and for the misalignment of the income statements' data pushed the GM to not customize the ERP by introducing the sales quotation module.

Reasons for this are attributed to the high reputation that SAP and the information it provided, directly or indirectly, had among users. At Tulip, in fact, the belief that information was "certified" and "ironclad" meant that not only people did not question its reliability, but they also reduced the problem to one of representation, rather than of substance.

Therefore, the paper contributes to research on the relationship between ERP systems and MASs by emphasizing that, besides focusing attention on the direction of this relationship and on its technical aspects, it is also necessary to investigate the impact that the implementation of an ERP system can have on people and their perceptions. This seems to be an area open to further research.

To conclude, the limitations of this study are also highlighted. One of the aspect analyzed in this paper is referred to the influence that SMEs' features had on the bidirectional relationship between ERP systems and MASs. Since the paper is based on a case study research carried out in an Italian company, these findings have to be intended as exploratory and they cannot be generalized to other organizations. Further research is therefore needed on this aspect. 


\section{References}

Ahrens T., Chapman C.S. (2007), Management accounting as practice, Accounting, Organizations and Society, 32, 1-2, pp. 1-27.

Ahrens T., Dent. J.F. (1998), Accounting and Organizations: Realizing the richness of field research, Journal of Management Accounting Research, 10, pp. 1-39.

Alcouffe S., Berland N., Levant Y. (2008), Actor-Networks and the diffusion of management accounting innovations: a comparative study, Management Accounting Research, 19, pp. 1-17.

Barretta A. (1999), Struttura organizzativa e controllo di gestione nelle PMI italiane, Rivista dei Dottori Commercialisti, 50, 2, pp. 241-264.

Bruns W.J., Waterhouse J.H. (1975), Budgetary control and organization structure, Journal of Accounting Research, 13, 2, pp. 177-203.

Burchell S., Clubb C., Hopwood A.G. (1985), Accounting in its social context: towards a history of value-added in the United Kingdom, Accounting, Organizations and Society, 10, 4, pp. 381-413.

Caglio A. (2003), Enterprise resource planning systems and accountants: toward hybridization?, European Accounting Review, 12, 1, pp. 123-153.

Chiucchi M.S. (2009), Lo studio di caso nel management accounting, Ancona, Clua.

Corbetta P. (2003), La ricerca sociale: metodologia e tecniche, vol. I, Paradigmi di riferimento, Bologna, Il Mulino.

Dechow N., Granlund M., Mouritsen J. (2006), Management Control of the complex organization: relationships between management accounting and information technology, Handbook of Management Accounting Research, Amsterdam, Elsevier.

Dechow N., Mouritsen J. (2005), Enterprise resource planning systems, management control and the quest for integration, Accounting, Organizations and Society, 30, 7-8, pp. 691733.

Denzin N.K., Lincoln Y.S., eds (1998), Collecting and interpreting qualitative material, Thousand Oaks, Sage.

Eisenhardt K. (1989), Building theories from case study research, Academy of Management Review, 14, 4, pp. 532-550.

Fattore G. (2005), Metodi di ricerca in economia aziendale, Milano, Egea.

Ferman J.E. (1999), Strategies for successful ERP connections, Manufacturing Engineering, 123, 4, pp. 48-60.

Franco M., Bourne M. (2003), Factors that play a role in "managing through measures", Management Decision, 41, 8, pp. 698-710.

Grabski S., Leech S.A., Sangster A. (2009), ERP implementations and their impact upon management accountants, Journal of Information Systems and Technology Management, 6, 2, pp. 125-142.

Grandlund M., Malmi T. (2002), Moderate impact of ERPS on management accounting: a lag or permanent outcome?, Management Accounting Research, 13, pp. 299-321.

Grandlund M., Mouritsen J. (2003), Introduction: problematizing the relationship between management control and information technology, European Accounting Review, 12, 1, pp. 77-83.

Guba E.G., Lincoln Y.S. (1998), Competing paradigm in qualitative research, in Denzin N.K., Lincoln Y.S. editor, The landscape of qualitative research, Thousand Oaks, Sage.

Guilding C. (1999), Competitor-focused accounting: an exploratory note, Accounting, Organizations and Society, 24, 7, pp. 583-595. 
Gupta A. (2000), Enterprise Resource Planning: the emerging organizational values systems, Industrial Management \& Data Systems, 100, 3, pp. 4-16.

Hill S. (1997), The wait is over, Manufacturing Systems, 15, 6, pp. 2-10.

Hunton J.E., Lippincott B., Reck J.L. (2003), Enterprise resource planning systems: comparing firm performance of adopters and nonadopters, International Journal of Accounting Information Systems, 4, pp. 165-184.

Hyvönen T. (2003), Management accounting and information systems: ERP versus BOB, European Accounting Review, 12, 1, pp. 155-173.

Hyvönen T. (2010), Exploring management accounting change in ERP context, Tampere, Coronet Books Incorporated.

Hyvönen T., Järvinen J., Pellinen J. (2008), A virtual integration. The management control system in a multidimensional enterprise, Management Accounting Research, 19, pp. 45-61.

Hyvönen T., Järvinen J., Pellinen J., Rahko T. (2009), Institutional logics, ICT and stability of management accounting, European Accounting Review, 18, 2, pp. 241-275.

Ifinedo P. (2008), Impacts of business vision, top management support and external expertise on ERP success, Business Process Management Journal, 14, 4, pp. 551-568.

Jack L., Kholeif A. (2008), Enterprise resource planning and a contest to limit the role of management accountants: a strong structuration perspective, Accounting Forum, 32, pp. 30-45.

Kamhawi E.M., Gunasekaran A. (2009), ERP systems implementation success factors: IS and non-IS managers' perceptions, International Journal of Business Information Systems, 4, 6, pp. 688-704.

Libby T., Waterhouse J.H. (1996), Predicting change in management accounting systems, Journal of Management Accounting Research, 8, 137-150.

Lodh S.C., Gaffikin M.J.R. (2003), Implementation of an integrated accounting and cost management system using the SAP system: a field study, European Accounting Review, 12, 1, pp. 85-121.

Luft J., Shields M.D. (2003), Mapping management accounting: graphics and guidelines for theory-consistent empirical research, Accounting, Organizations and Society, 28, 2-3, pp. 169-249.

Marchi L. (2003), I sistemi informativi aziendali, Milano, Giuffrè.

Marchi L. (2009), Il processo di controllo, in Marasca S., Marchi L., Riccaboni A. editor, Controllo di gestione. Metodologie e strumenti, Arezzo, Knowità.

Marchini I. (1995), Il governo della piccola impresa, vol. I, Le basi delle conoscenze, Genova, ASPI/INS-EDIT.

Matolcsy Z.P., Booth P., Wieder B. (2005), Economic benefits of enterprise resource planning systems: some empirical evidence, Accounting and Finance, 45, pp. 439-456.

Merchant K.A. (1981), The design of the corporate budgeting system: influences on managerial behavior and performance, The Accounting Review, 56, 4, pp. 813-829.

Muscatello J.R., Small M.H., Chen I.J. (2003), Implementing enterprise resource planning (ERP) systems in small and midsize manufacturing firms, International Journal of Operations \& Production Management, 23, 8, pp. 850-871.

Nicolau A.I. (2004), Firm performance effects in relation to the implementation and use of enterprise resource planning systems, Journal of Information Systems, 18, 2, pp. 79-105.

O’Leary D.E. (2000), Enterprise resource planning systems: systems, life cycle, electronic commerce and risk, Cambridge, Cambridge University Press.

Patton M.Q. (1990), Qualitative evaluation and research methods, 2nd ed., Beverly Hills, Sage. 
Poston R., Grabski S. (2001), Financial impact of enterprise resource planning implementation, International Journal of Accounting Information Systems, 2, pp. 271-294.

Quattrone P., Hopper T. (2001), What does organizational change mean? Speculations on a taken for granted category, Management Accounting Research, 12, pp. 403-435.

Riccaboni A. (2004), Il cambiamento nei sistemi di controllo: la dimensione «immateriale», Controllo di Gestione, 1, 1, pp. 19-25.

Rom A., Rohde C. (2007), Management accounting and integrated information systems: a literature review, International Journal of Accounting Information Systems, 8, pp. 40-68.

Ryan B., Scapens R.W., Theobald M. (2002), Research method \& methodology in Finance $\&$ Accounting, $2^{\text {nd }}$ ed., London, Thomson.

Sangster A., Leech S.A., Grabski S. (2009), ERP implementations and their impact upon management accountants, Journal of International Systems and Technology Management, 6, 2, pp. 125-142.

Scapens R.W. (1990), Researching management accounting practices: the role of case studies methods, British Accounting Review, 22, 3, pp. 259-281.

Scapens R.W. (2004), Doing case study research, in Humprey C. and Lee B.H.K editor, The real life guide to accounting research: a behind-the-scene view of using qualitative research methods, Oxford, Elsevier Ltd.

Scapens R.W., Jazayeri M. (2003), ERP systems and management accounting change: opportunities or impacts? A research note, European Accounting Review, 12, 1, pp. 201-233.

Schlichter B.R., Kraemmergaraad P. (2010), A comprehensive literature review of the ERP research field over a decade, Journal of Enterprise Information Management, 23, 4, pp. 486-520.

Umble E.J., Haft R.R., Umble M.M. (2003), Enterprise resource planning: Implementation procedures and critical success factors, European Journal of Operational Research, 146, pp. 241-257.

Wagner E.L., Moll J., Newell S. (2011), Accounting logics, reconfiguration of ERP systems and the emergence of new accounting practices: a sociomaterial perspective, Management Accounting Research, 22, pp. 181-197.

Yin R. (2003), Case study research: design and methods, $3^{\text {rd }}$ ed., Thousand Oaks, Sage. 


\section{Appendix 1}

\section{The company profile}

Tulip S.p.A. is a medium-sized Italian manufacturing company operating worldwide and whose production system is based on job orders.

Since it was established, in the Forties, Tulip has grown considerably, thanks to a strong investment policy that led the company to diversify its production and to double the products manufactured in just a few years. The company began to export its products in the Eighties but the "true" internationalization process began at the end of the Nineties: in five years' time, in fact, three commercially affiliated companies were established abroad. Since 2007, after this long period of growth, Tulip has experienced a process of downsizing with deep structural changes substantially due to the global crisis: one of the foreign companies has been closed and the majority of the Italian manufacturing companies, which were part of the group, have been merged within the same firm. After the re-organization in 2010, Tulip's turnover is around 41 million Euros and the number of employees is approximately 200.

\section{The management accounting system in Tulip before the SAP imple- mentation}

The analysis of the existing MAS in Tulip can be conducted adopting a technical perspective, in which attention is focused on the techniques that are used and on the way the MAS is called upon to work within the organization, and a data processing perspective which looks at the information tools through which managerial information is provided (Marchi, 2003).

The MAS in Tulip was very simple before the SAP implementation. It was essentially based on the control of the production job orders whose cost was the most relevant information that the MAS was required to provide. Costs were calculated monthly and only for the already fulfilled orders. Thanks to this information, the job order gross margin was determined and it was used to analyze the actual profitability of sales.

In terms of forward-looking information, a budget was prepared, where costs were estimated on the basis of those borne over the previous year and considering the expected number of products to be manufactured. With re- 
gard to the cost of raw materials, which represent about $70 \%$ of the production cost, data were directly provided by the GM who was considered the most important person able to make market forecasts and to use these data to estimate this kind of costs.

As far as the managerial reporting system is concerned, it was essentially composed of two reports: the "institutional report", and the production report. The former was produced every month and it was addressed to the Board. It was aimed at analyzing company performance over the period under scrutiny. The latter, instead, offered an in-depth analysis of technical information on lot products, set-up and machine hours referred to every manufacturing line within every plant. This report was addressed to the production managers who used it in order to conduct an in-depth analysis of their Departments' results as well as their weak points so as to improve the organization of the production process and eliminate the inefficiencies that had come to light.

Another important aspect that needs to be highlighted is the role of Tulip's management accountant and his organizational position. The management accountant was the provider of the abovementioned information and reports, he did not directly participate in meetings in which results were discussed but rather indirectly, through the mere description of the results included in the managerial reports produced. More specifically, with regard to the institutional report the controller had a prior informal meeting with the GM where he was involved in the description of the most relevant information provided and in the selection of specific information to be presented to the Board. Nonetheless, only the GM presented and discussed the results with the Board. The situation was partially different for the production report. In this case, in fact, there were no formal moments in which the controller discussed the results with the production managers: he simply sent the production report to them every month and he added very brief comments to the data presented. In light of this, it seems that the main controller's task was that of an information provider.

The other analysis perspective from which to look at the MAS before the SAP implementation is that of the data processing system. The whole information system was managed through a legacy system based on the Applicazioni Contabili Gestionali (ACG) of IBM. Managerial accounting information was produced by processing data obtained by the ACG on Excel spreadsheets with a consequent high risk of making mistakes. At the same time, the huge amount of time needed to process data using Excel spreadsheets limited the likelihood of being able to provide ad hoc and timely information, especially when it was particularly complex and diffi- 
cult to produce. In order to overcome this problem, the controller often asked for the help of the IT Department to make customized applications as this was the best way to provide the requested information to end users.

\section{The decision to implement SAP}

SAP was implemented in 2005 after a software selection which took place from January 2004. The Head of the IT Department and the company controller were in charge of the software selection and, during this period, they analyzed several ERPs; finally, SAP was chosen. Many reasons drove the decision to adopt SAP. They are linked both to technical aspects and to what people expected from the SAP implementation, in terms of advantages that it should have been able to bring about within the organization.

From a technical standpoint, SAP was the only system which allowed Tulip to incorporate the so called "product configurator" in the new ERP system, among those which were analyzed during the software selection stage. The product configurator was the heart of the company information system. Every time that an order was placed, it was entered and sales, design and production managers were called to enter the data the product configurator requested with regard to their specific roles. At the end, the whole production process was planned and defined in every single aspect. The data concerning the way the order should have been executed represented a fundamental input for the management accountant who was called upon to calculate the cost of the whole order and who used these data also for budgeting, profitability analysis, etc. From a technical standpoint, the possibility to incorporate the product configurator in the new ERP system was the main reason which influenced the decision to choose SAP.

With regard to people's expectations, instead, the owner played a pivotal role. The successful experience of the other companies he came into contact with had convinced him of the validity of this ERP system; therefore, he was absolutely sure of its usefulness and of the potential benefits the implementation of the ERP system could bring to his company.

"At the end, the choice was SAP because the owner said: we want SAP. And this shows a fundamental aspect: without this sponsorship we could not have achieved our results. Sponsorship is fundamental.”

[Company Controller]

In a parallel fashion, SAP had gained a strong reputation also among top 
management. At that time, in fact, SAP was one of the best known ERP systems and it was used by several large companies. Moreover, company consultants that had already followed the whole implementation of the existing system in Tulip presented it as the best choice for the company. As a consequence, managers assumed that the new ERP, being widespread and implemented in various companies bigger than Tulip and with more sophisticated processes and being so supported by people they completely trusted, could easily fulfill the company needs as far as planning and control process was concerned. Their perception was also that SAP could offer plenty of opportunities to improve the company MAS.

\begin{abstract}
"[...] We wanted to have a product able to satisfy our needs, especially with regard to the MAS which was very simple at that moment. I do not think that the way SAP manages the accounting functions is not OK for us. I can understand that it's not ok for a big firm, like ENI for instance, because ENI is a complex organization, but we are not as complex as it is. When selecting the new ERP, we said: we will accept every opportunity SAP offers because if we are able to do what SAP does, our MAS will be surely better than before. Of course, the people who developed SAP have taken into consideration several aspects that we would not be able to consider by ourselves. So, what SAP can offer us is surely something better than what we have now.”
\end{abstract}

[Head of IT Department]

Something very similar was thought by the controller as well. In fact, he looked at SAP as a great chance to improve the quality of the information provided by the MAS.

"SAP rigidity allows us to obtain reliable data and I believe that this is very
important for an accountant. You can be sure about the reliability of proce-
dures through which you obtain those data. I can reconstruct the way infor-
mation is provided."

[Company Controller]

There was evidence, in essence, that one of the most significant advantages in adopting SAP was that it could guarantee that information would be provided by a single source and that it would be precise and correct: this was considered to be of the utmost importance by the controller as it would bring about a relevant improvement of the MAS.

As for the adoption stage of SAP, it was implemented using a sort of "step by step" approach. After having verified, through a pilot project, that SAP was the only ERP system among those which participated in the selec- 
tion able to incorporate the product configurator, the SAP implementation was launched. It began with the administration and controlling module and progressively, all the other modules were added. In just under 18 months the implementation was accomplished.

\section{Appendix 2}

\section{List of acronyms}

ACG: Applicazioni Contabili Gestionali, namely a set of applications used to satisfy the information needs of specific company areas

CFO: Chief Financial Officer

ERP: Enterprise Resource Planning

GM: General Manager

IT: Information Technology

MAS: Management Accounting System

SME: Small and Medium-sized Enterprise 